\title{
Outcome of Snodgrass Repair in Distal Hypospadias - An Institutional Experience
}

\author{
Deepak K Thakur \\ Department of Urology, Birat Medical College- Teaching Hospital, Biratnagar, Nepal.
}

Correspondence: Dr Deepak K Thakur, Consultant Urologist, Department of Urology, Birat Medical College-

Teaching Hospital, Biratnagar, Nepal.

E-mail: yoursdeepak2000@gmail.com

\begin{tabular}{l} 
Abstract \\
\hline \hline Introduction: Hypospadias is a common congenital anomaly in which the urethral opening \\
is on the ventral surface of the penis, often associated with ventral curvature of penis \\
(chordee). Many techniques have been descried in the literature for the repair of hypospadias with \\
variable results. This study aimed at outcome following Snodgrass repair in distal hypospadias by \\
a single Urologist. \\
Methods: This was a retrospective study conducted at Department of Urology, Birat Medical \\
College from December 2017 to January 2019 during which 16 patients with distal hypospadias \\
underwent primary repair using Snodgrass technique. \\
Results: Mean age was 5.12 years and duration of operation was 136.25 minutes. About $56.25 \%$ \\
of cases were subcoronal and $43.25 \%$ were coronal. Chordee of $<30$ degree was present in $25 \%$ of \\
cases. Complications occurred in $25 \%$ cases of which half (12.5\%) were urethrocutaneous fistula \\
and rest were meatal stenosis (6.25\%) and hematoma (6.25\%). \\
Conclusion: The outcome of Snodgrass repair in distal hypospadias is satisfactory with acceptable \\
complications and urethrocutaneous fistula is the commonest complication. \\
Keywords: Chordee; Hypospadias; Snodgrass repair.
\end{tabular}

\section{Introduction}

Hypospadias is one of the most common congenital anomalies of the male children affecting 1 in $300 .{ }^{1}$ Urethral meatus lies on the ventral surface of penis proximal to its normal position, anywhere from below the tip of the glans to the perineum. Hypospadias is divided into three types - posterior (proximal), middle and anterior (distal), regarding the position of meatus. In anterior type, meatal orifice opens either on distal penile shaft, on corona, or below the tip of glans. ${ }^{2}$ Distal hypospadias is the commonest type accounting for 50\%-70\%. ${ }^{3-4}$

Different techniques have been described for the repair of hypospadias which is a challenging job and there is a learning curve for every surgeon. ${ }^{5}$ The multiple surgical options available for hypospadias repair are a testament to the fact that no surgical procedure guarantees universal success by all surgeons. As is true for all reconstructive procedures, the best chance of a good outcome is with the first operation. ${ }^{6}$ Certain factors like location of the meatus and the degree of proximal spongiosal hypoplasia, presence and degree of VC, quality (width and depth) of the urethral plate, size of the glans and the depth of the navicular fossa, degree of ventral skin deficiency, scrotal abnormalities, availability of foreskin and penile lengh are key factors for operative planning ${ }^{7-8}$ The surgical management of hypospadias aims to achieve:a straight penis with a slit-shaped and adequate caliber meatus at the apex of the glans , a conical reconfigured glans and an acceptable cosmetic outcome. ${ }^{9}$ Surgical intervention for hypospadias can be performed at any age, but, most researchers recommend operative intervention at 6-18 months to limit physiological and psychological stress of surgery. ${ }^{10}$

The Tubularized Incised Plate(TIP) procedure proposed by Snodgrass involves a midline incision of the UP to widen it and achieve a better caliber urethra, which is then tubularized. ${ }^{11}$ The superior cosmetic results and the low 
incidence of complications has led to wide consensus that the TIP urethroplasty is the most commonly used technique for distal hypospadias ${ }^{12 T h e}$ objective of this study is to assess the outcome of distal hypospadias repair using Snodgrass technique.

\section{Methods}

This was a retrospective study conducted at Department of Urology, Birat Medical College Nepal from December 2017 to January 2019. The inclusion criteria were children with distal hypospadias aged above one year without prior intervention. Children aged less than one year, proximal hypospadias and previous attempted repair were excluded. Patients characteristics and family history were traced. Local examination findings emphasizing position of the urethral meatus, urethral plate status, presence of prepuce and degree of chordee were documented. All children were evaluated preoperatively as per the institutional protocol. All patients received injections ceftriaxone $(50 \mathrm{mg} / \mathrm{kg}$ ) and gentamycin $(5 \mathrm{mg} / \mathrm{kg})$ as prophylactic antibiotics. The procedure was done under general anesthesia with 1:1 dilution of xylocaine plus adrenaline infiltration along incision lines. The key operative steps included (Fig.1):

- Circumcising incision

- Penile degloving and correction of chordee confirmed by artificial erection by corporal saline injection

- Urethral plate mobilization

- Urethral plate incision and tubularization by subepithelial running stiches over feeding tube as a stent

- Tubularization was reinforced by spongioplasty, dartos flap and Byar's flap respectively

- Glansoplasty

Polyglactin 5/0 was used for repair and circumcising incision was closed by $4 / 0$ chromic cat gut . Wound was dressed with topical mupirocin ointment and dry cotton. Postoperatively all children received ceftriaxone and gentamycin injections during hospital stay in addition to analgesics and other supportive treatments. Dressing was removed on third postoperative day and thereafter normal saline cleaning and topical mupirocin ointment application was continued until the stent was removed which was usually done on $7^{\text {th }}$ postoperative day and patient was discharged to follow up after one month and three months or whenever required. During each visit, voiding pattern was observed with postvoid residual urine whenever required.

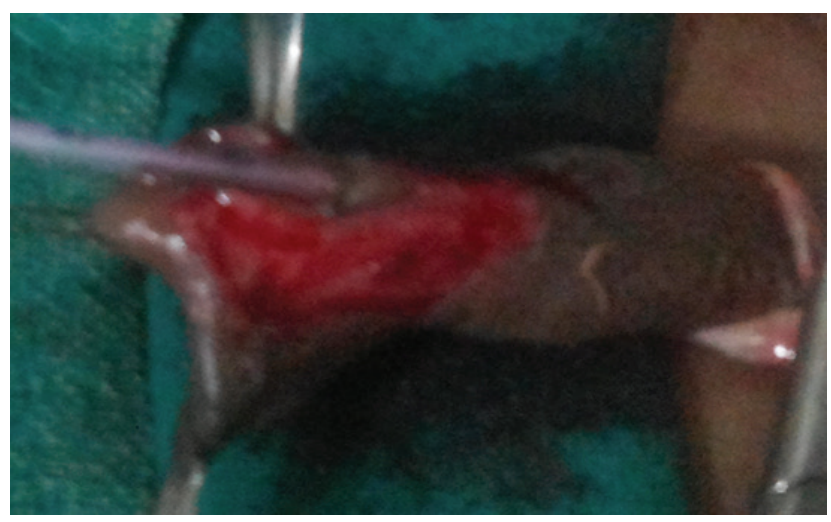

Figure 1: Urethral plate ready for tubularization

\section{Statistical Analysis}

Data were analyzed using SPSS 20. Statistical averages were calculated.

\section{Results}

Sixteen children met the inclusion criteria and they were included in the study. Mean age was 5.12 \pm 1.40 years - About 56.25\% (9/16) of cases were subcoronal and $43.75 \%(7 / 16)$ were coronal. Chordee of $<30$ degree measured intraoperatively, was present in $25 \%(4 / 16)$ of cases. Mean duration of operation was $136.25 \pm 11.18$ minutes and duration of hospital stay was $7.43 \pm 1.03$ days . Complications occurred in $25 \%(4 / 16)$ cases. Two of the cases $(12.5 \%)$ developed urethrocutaneous fistula on $5^{\text {th }}$ postoperative day (Fig 2$)$. One case $(6.25 \%)$ had proximal penile shaft hematoma which resolved with conservative management and another case(6.25\%)developed meatal stenosis during follow up at one month. It was managed by meatal dilatation and his voiding was satisfactory at the third follow up month.

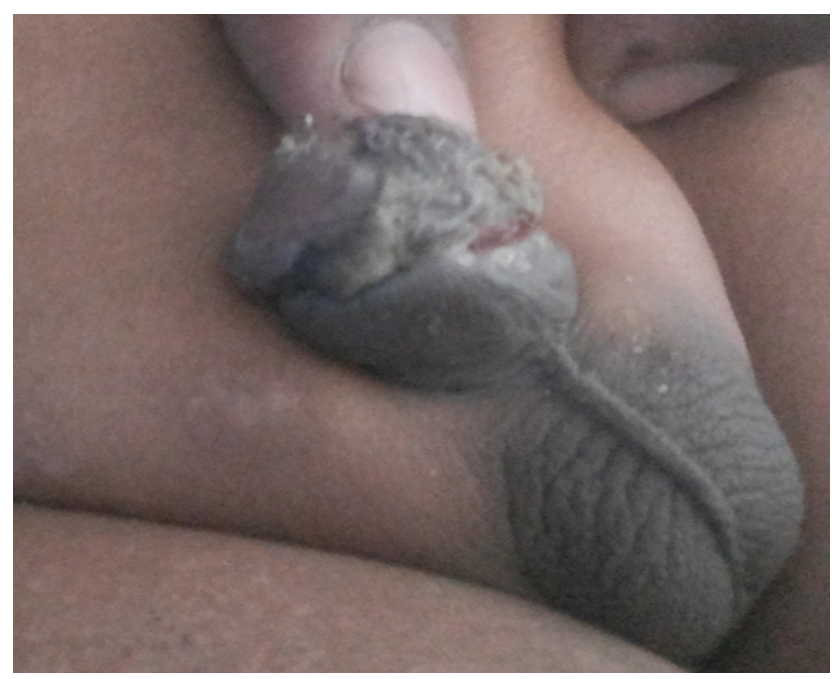

Figure 2: Urethrocutaneous fistula 


\section{Discussion}

Hypospadias is one of the most common congenital anomalies of the male children affecting 1 in $300{ }^{1}$ Distal hypospadias is the commonest type accounting for $50 \%-70 \%{ }^{3-4}$ Different techniques have been described for the repair of hypospadias and there is a learning curve for every surgeon. ${ }^{5}$ There is no one standard procedure for all hypospadias repair. A technique must be adapted for each individual patient. MAGPI(Meatal Advancement and Glansoplasty), Mathieu and Snodgrass are the most commonly used techniques. The superior cosmetic results and the low incidence of complications has led to wide consensus that the TIP urethroplasty is the most commonly used technique for distal hypospadias ${ }^{12}$ This study also aimed at observing the outcome of distal hypospadias repair using Snodgrass technique.

The mean age of repair was 5.12 years here. In an another study involving 31 children, the median age of repair was 5.8 years comparable with present study. ${ }^{13}$ This is above the recommended age of intervention by the most authors which is 6-18 months of age to limit the psychological stress and subsequent behavioural problems. ${ }^{10}$ But the reports are conflicting regarding whether increasing age at surgery increases complications. ${ }^{14-15}$

Subcoronal locatin of the meatus was the most common variant of distal hypospadias accounting for $56.25 \%$ and incidence of chordee was $25 \%$ in this study. This is comparable with $51.6 \%$ and $19.4 \%$ respectively in another study. ${ }^{13}$ Contrary to this, Barcat reported $15 \%$ incidence of chordee in distal hypospadias. ${ }^{16}$ This difference may be attributable to geography.

Polyglactin suture of 5/0 was used for repair here. This is in accordance with the others suggesting fine polyglactin sutures for repair. ${ }^{13,17}$

Complication rate of distal hypospadias repair is variable and also depends on multiple factors as stated above. Most studies report complication of 5\%-10\% after distal hypospadias repair ${ }^{9}$ which is lower than $25 \%$ complication rate in this study. this higher complication rate can be due to the learning curve of the urologist The most common complications are urethrocutaneous fistula and meatal stenosis. In a study involving 31 cases of distal hypospadias using Snodgrass technique, fistula and meatal stenosis was reported in $16.1 \%$ and $6.5 \%$ of cases respectively. ${ }^{13}$ Another study with 59 children and 9 months of follow up reported fistula in $10 \%$ of cases and meatal stenosis in $5 \%$ of cases. ${ }^{18}$ In the current study, fistula was seen in two cases (12.5\%) and meatal stenosis in one case $(6.25 \%)$. The child with meatal stenosis is doing fine after meatal dilatation and the children with fistula are planned for reassessment and further intervention after 6 months of surgery.

\section{Conclusion}

The outcome of Snodgrass repair in distal hypospadias is satisfactory with acceptable complications and urethrocutaneous fistula is the commonest complication.

\section{Limitation}

The study is limited by its retrospective nature. Less number of patients and inclusion of only distal hypospadias are other limitations to project outcome of the procedure in hypospadias.

\section{Conflict of Interest}

None. Declared.

\section{Acknowledgement}

I am thankful to medical record section of Birat Medical College for proper maintenance of the records.

\section{References}

1. Duckett JW, Snyder HM. The MAGPI hypospadias repair in 1111 patients. Ann Surg, 1991; 213(6): 620-5.

2. BasharatAk, Muhamad AS, Faras BK. Comparative Study of Inverting Suturing Versus Overand Over Continues Suturing in Hypospadias Repair. J Ayub Med Coll Abbottabad, 2009; 21(4).

3. Churi, F. J., Hardy, B. E. and Churchill, B. M.: Urologic anomaliesassociated with hypospadias. Urol. Clin. North Am 1981; 8: 565 — 571.

4. Belman $\mathrm{AB}$ and Kass $\mathrm{EJ}$ : Hypospadias repair in children less than 1 year old. J Urol 1982; 128: 1273

5. Warren, Snodgrass. Hypospadias. Pediatrics in Review (the official journal of the American Academy of Pediatrics). 2004; 25:63-67.

6. Snodgrass WT, Bush NC. Reoperative urethroplasty after failed hypospadias repair: How prior surgery impacts risk for additional complications. J Ped Urol. 2016.

7. Cimador M, Vallasciani S, Manzoni G, et al. Failed hypospadias in pediatric patients. Nat Rev. 2013;10:657-65. https://doi.org/10.1038/ nrurol.2013.164.

8. Snodgrass W, Macedo A, Hoebeke P, et al. Hypospadias dilemmas: A round table. J Pediatr Urol. 2011;7:14557. https://doi.org/10.1016/j.jpurol.2010.11.009. 
9. Melise A. Keays and Sumit Dave. Current hypospadias management: Diagnosis, surgical management, and long-term patient-centred outcomes. Can Urol Assoc J 2017;11(1-2Suppl1):S48-53. http://dx.doi. org/10.5489/cuaj.4386

10. Manzoni G, Bracka A, Palminteri E, et al. Hypospadias surgery: When, what, and by whom? BJU Int .2004;94:1188-95. https://doi.org/10.1046/j.1464410x.2004.05128.x

11. Snodgrass W. Tubularized, incised plate urethroplasty for distal hypospadias. J Urol 1994;151:464-5.

12. Steven L, Cherian A, Yankovic F, et al. Current practice in pediatric hypospadias surgery: A specialist survey. J Pediatr Urol.2013;9:1126-30. https://doi. org/10.1016/j.jpurol.2013.04.008

13. Yassir H A Ismail, Omar A M Khair \& Atahir Bagadi Outcome of Distal Hypospadias Repair in Pediatric Surgery Department at Alribat Teaching Hospital. Global Journal of Medical Research. $2013: 13 ; 5$

14. Yildiz T, Tahtali IN, Ates DC, et al. Age of patient is a risk factor for urethrocutaneous fistula in hypospadias surgery. J Pediatr Urol .2013;9: 900-3. https://doi. org/10.1016/j.jpurol.2012.12.007
15. Lu W, Tao Y, Wisniewski AB, et al. Different outcomes of hypospadias surgery between North America, Europe, and China: Is patient age a factor? Neuphrourol Mon 2012;4:609-12. https://doi. org/10.5812/numonthly. 1853

16. Barcat, J.: Current concepts of treatment. In Horton C.E. (ed.): Plastic and Reconstructive surgery of the genital area. Boston, Little, Brown Co., pp. 249263,1973

17. Bush NC, Barber TD, Dajusta D, Prieto JC, Ziada A and Snodgrass W.Results of distal hypospadias repair after pediatric urology fellowship training: A comparison of junior surgeons with their mentor. J Pediatr Urol. 2016 Jun;12(3):162.e1-4. doi: 10.1016/j. jpurol.2015.12.007. Epub 2016 Jan 20.

18. Holland AJ, Smith GH, Cass DT. Clinical review of the 'Snodgrass' hypospadias repair. Aust N Z J Surg. 2000; 70: 597-600. 